\title{
EDUCAÇÃO DOCAMPO E PEDAGOGIA DA ALTERNÂNCIA NO BRASIL E NA AMAZÔNIA: BASES HISTÓRICAS
}

\author{
Maria Sueli Corrêa dos Prazeres ${ }^{1}$
}

\section{RESUMO}

$\mathrm{O}$ artigo tem como objetivo refletir sobre a Educação do Campo e a Pedagogia da Alternância no Brasil e na Amazônia. No primeiro momento retrata o contexto histórico da Educação do Campo, enfocando os desafios do Movimento Por Uma Educação do Canpo destacando a necessidade de políticas públicas para o contexto amazônico, apontando as demandas e as perspectivas da educação para o meio rural. No segundo momento contextualiza a Pedagogia da Alternância focalizando sua origem, questões conceituais, situando a mesma no Estado do Pará. O movimento por uma educação do campo constituído por movimentos sociais que se organizam a partir do campo e que têm apoio de educadores, intelectuais, universidades públicas e organizações não-governamentais. Este movimento, desde a década de 1990, vem constituindo uma discussão teórica sobre a educação do campo como estratégia contra hegemônica frente às políticas do Estado brasileiro direcionadas às populações do campo. Em nosso país o desenvolvimento da Pedagogia da Alternância ganha materialidade como estratégia de inúmeros movimentos sociais organizadas nos Centros Familiares de Formação em Alternância (CEFFAS). É importante enfatizar que a proposição tem sido utilizada como estratégia para garantir a participação de amplos segmentos da sociedade nas decisões e encaminhamentos, garantindo assim, a educação aos filhos dos sujeitos do campo.

Palavras-chaves: Educação do Campo; Pedagogia da Alternância; Bases Históricas; Amazônia.

\section{RURAL EDUCATION AND PEDAGOGY OF ALTERNATION IN BRAZIL AND THE AMAZON: HISTORICAL BASES}

\begin{abstract}
The article aims to reflect on Rural Education and Pedagogy of Alternation in Brazil and the Amazon. At first portrays the historical context of Field Education, focusing on the challenges of the Movement For An Education Canpo highlighting the need for public policies for the Amazon region, pointing the demands and prospects of education in rural areas. In the second contextualizes the Pedagogy of Alternation focusing its origin, conceptual issues, placing the same in the State of Para The movement for an education field consists of social movements that are organized from the field and have the support of educators, intellectuals, public universities and nongovernmental organizations. This movement since the 1990s, has constituted a theoretical discussion of rural education as a strategy against hegemonic policies ahead of the Brazilian populations directed to the field. In our country the development of the Pedagogy of Alternation wins materiality as a strategy of numerous social movements organized in Family Centers Training Switching (CEFFAs). It is important to emphasize that the proposition has been used as a strategy to ensure the participation of broad segments of society in decisions and referrals, thereby ensuring education to the children of the subject field.
\end{abstract}

Keywords: Rural Education. Pedagogy of Alternation. Historical bases. Amaônia 


\section{Educação do campo na Amazônia: movimento histórico}

Nas últimas três décadas em diferentes estados brasileiros, vêm se desenvolvendo diversas experiências educativas no campo brasileiro que objetivam fortalecer alternativas que atendam as necessidades e os desafios pautados pelo momento histórico. $\mathrm{O}$ Movimento Por uma Educação do Campo ganha força no final dos anos de 1970, momento em que inúmeras experiências de educação popular vinham se fortalecendo e passavam a reivindicar não somente acesso à terra, mas também outras demandas sociais, como por exemplo, a educação.

A partir de 1997 esse movimento se fortalece com a realização do I Encontro Nacional de Educadores e Educadoras da Reforma Agrária (I ENERA). Com a realização do I ENERA, organizado pelo Movimento dos Trabalhadores Rurais Sem Terra (MST) foram lançadas as premissas fundamentais que serviriam de base ao movimento que se fortaleceria nos anos seguintes. Ainda em 1998, foi constituída a Articulação Nacional Por uma Educação Básica do Campo, com objetivo de dar continuidade à mobilização em defesa da Educação do campo, composta pelas seguintes entidades: Confederação dos Bispos do Brasil (CNBB), Movimento dos Trabalhadores Rurais Sem Terra (MST), Universidade de Brasília (UNB), Organização das Nações Unidades para a Educação, Ciência e Cultura (UNESCO), Fundo das Nações Unidas para a Infância (UNICEF).

Em 1998 e 2004 temos respectivamente a realização da I Conferência Nacional: Por uma Educação Básica no Campo e II Conferência de Educação do Campo, fruto de questionamentos apontados no I ENERA, com a participação de diversas instituições e movimentos sociais. O Texto Base da I Conferência Por uma Educação do Campo (1999) destaca que os objetivos da Educação do Campo seria pensar em outro projeto de desenvolvimento para o país, visto que o projeto em curso excluía os diversos atores sociais do campo, depois incluir as demandas desses sujeitos na agenda política, através das políticas públicas para que estas pudessem promover a inclusão dos muitos brasileiros que vivem no campo.

Para Arroyo (1999, p. 32) “A Educação do Campo deve incorporar uma visão mais rica do conhecimento e da cultura, uma visão mais digna do campo, que será possível se situamos a educação, o conhecimento, a ciência, a tecnologia, a cultura como direitos". Para este autor, a luta situa-se no campo dos direitos que foram historicamente negados, o direito do trabalhador à educação. Esses direitos serão garantidos a partir de uma nova forma de pensar, entender e fazer a educação do campo, na busca de desconstruir a imagem das escolas do meio rural como atrasadas, pobre e fora do lugar no projeto de desenvolvimento do país. Para isso, deve haver um esforço para mudar a concepção que se tem do campo.

Nessa nova concepção, o campo surge como espaço de criação e recriação de processos educativos que defende os trabalhadores como sujeitos de direitos. Para que possa ser feita a inclusão torna-se necessários que esses sujeitos sejam reconhecidos, primeiramente como sujeitos de direitos, depois como protagonistas de seus processos educacionais. Nessa direção, Caldart (2002, p. 27) "A educação do campo se identifica pelos seus sujeitos". Para a autora, um aspecto fundamental da Educação do Campo é a própria identificação com seus sujeitos, ou seja, a educação do campo é para as pessoas que vivem no campo e deve ter em sua essência pedagógica e metodológica traços identitários dos sujeitos do campo, sendo estes pequenos agricultores, quilombolas, povos indígenas, pescadores, camponeses, assentados, reassentados, ribeirinhos, povos da floresta, caipiras, lavradores, roceiros, sem terra, caboclos, meeiros, bóia-fria e outros. 
De acordo com as análises do Grupo Permanente de Trabalho de Educação do Campo (2005, p. 11) "apesar da intensa urbanização ocorrida nas últimas décadas, cerca de um quinto da população do país encontra-se no meio rural". Ainda pontua que cerca de 32 milhões de habitantes da área rural encontra-se em franca desvantagem, tanto em termos de capital físico (recursos financeiros) quanto de capital sociocultural (escolaridade e frequiência à escola) em comparação aos que residem na área urbana. Pelos dados mencionados constata-se que esse quantitativo é muito expressivo e evidencia grandes desigualdades no campo brasileiro.

Prosseguindo, ainda conforme a escolarização dos sujeitos do campo, as disparidades aumentam principalmente quando comparados com os do espaço urbano. Os dados das escolas que estão situadas no meio rural mostram inúmeras desvantagens, desde distorções idade/série até o quantitativo daqueles alunos que permanecem fora da escola mesmo em idade escolar. Silva et al (2006, p. 71) destaca dados importantes para a reflexão.

Nas zonas rurais, $6 \%$ das crianças de 7 a 14 anos estão fora da escola, comparado a 3\% nas zonas urbanas. Dos jovens de 15 a 18 anos, 65,3\% estão matriculados, mas $85 \%$ deles apresentam defasagem de idade/série. Nas zonas urbanas a taxa de matrícula desse mesmo grupo etário é de $77,1 \%$, sendo que $65 \%$ apresentam defasagem idade série. O número médio de anos de escolarização da população adulta (com 25 anos de idade ou mais) residente na zona rural é de apenas três anos, comparado a 6,5 anos nas áreas urbanas. Um terço (36\%) da população adulta que vive no meio rural é considerada analfabeta.

Ao analisarmos esses percentuais, notamos claramente que existe um enorme distanciamento entre as oportunidades educacionais da área urbana e rural. Esse indicativo demonstra que é prioritária uma mudança no desenho das políticas públicas para esse setor, uma vez que as mesmas têm como consequiência o retrato educacional indicado acima. Apesar de nos últimos anos termos tido avanços significativos, se levarmos em consideração o acesso à educação, como indica o INEP (2007) "Com uma taxa de atendimento de $97,1 \%$ para a população de 7 a 14 anos e de freqüência líquida de 93,8\% no ensino fundamental para essa mesma faixa etária o acesso em termos nacionais, encontra-se próximo da universalização".

Contudo, os dados revelam que o grande impasse que se coloca não está mais centrado no acesso, mas na qualidade da educação que é ofertada. Tais estatísticas são reveladoras de uma realidade que precisa ter outros contornos, ter cor, cheiro e sabor. A ruralidade do campo precisa ser afirmada e com ela os anseios de milhões de brasileiros, sejam pelos dados dos órgãos oficiais ou pelas alternativas que se apresentem.

No Pará, vem sendo fortalecido um Movimento Paraense por uma Educação do Campo, que aglutina através do Fórum Paraense de Educação do Campo inúmeras entidades da sociedade civil, movimentos sociais, instituições de ensino, pesquisa, órgãos governamentais de fomento ao desenvolvimento e da área educacional. Como conjugação de esforços de diversos sujeitos públicos e sociais tem-se a realização dos Seminários Estaduais de Educação do Campo envolvendo um número significativo de sujeitos do campo e da cidade, para discutir, elaborar e propor ações inclusivas para o campo da Amazônia.

Nessa trajetória, tivemos em fevereiro de 2004 a realização do I Seminário Estadual de Educação do Campo com o tema "Educação do Campo e Desenvolvimento Rural na Amazônia"- o qual pautava a defesa de políticas públicas de desenvolvimento e educação 
do campo com qualidade social para as populações do campo, dos rios e das florestas. (II Seminário Estadual de Educação do Campo, 2005) contando com a presença de 700 pessoas. A realização do I Seminário sinaliza muitos desafios a serem enfrentados e culmina com a Carta de Belém (2004) onde inúmeros sujeitos públicos e sociais assumem o compromisso de trabalhar pela elaboração de políticas públicas de educação comprometidas com o desenvolvimento do campo, inclusão social e a valorização da diversidade e saberes das populações do campo.

Em junho de 2005, realizou-se no Município de Ananindeua o II Seminário Estadual de Educação do Campo, das Florestas e das Águas da Amazônia Paraense, contando com a presença de 630 participantes. O Seminário buscou apontar diretrizes, proposições e encaminhamentos para a Educação do Campo, e seguiu, como aponta o Manifesto do II Seminário (2005, p. 04), na perspectiva de "ruptura com a lógica de exploração e expropriação das riquezas naturais, sociais e culturais, que historicamente e sistematicamente tem gerado benefícios alheios aos interesses das populações amazônicas".

No ano de 2007 foi realizado o III Seminário Estadual de Educação do Campo e o I Seminário Estadual da Juventude do Campo e contou com a presença de 1.200 participantes. O Caderno de Textos do III Seminário Estadual de Educação do Campo (2007) pontua que "os desafios remetem para aprofundar formulações, proposições e mobilizações no âmbito do Plano Estadual de Educação do Pará e das políticas públicas para o campo". Dentre as propostas que consta no manifesto destacam-se: a construção coletiva do currículo, a partir da experiência e acúmulo de seus sujeitos e da comunidade local; a flexibilização do calendário escolar; a incorporação de componentes curriculares que valorizam o tempo e o espaço amazônico, a constituição dos modos de vida das populações tradicionais; a valorização da identidade dos sujeitos e dos movimentos sociais no campo e autonomia para as escolas do campo.

Além desses desafios, o manifesto aponta para o fortalecimento da Pedagogia da Alternância no campo paraense, ao pontuar como um dos desafios o reconhecimento pelo Conselho Estadual de Educação das experiências dos Centros Familiar de Formação por Alternância (CEFFA's) e reconhecer a Pedagogia da Alternância como política pública no âmbito da Educação do campo. Como se percebe, a realização dos seminários estaduais tem sido um grande avanço para reafirmar canais de discussão e proposições de políticas que atenda a diversidade dos sujeitos do campo, assim como, legitimar de fato e de direito políticas que já vêm acontecendo, como é o caso da Pedagogia da Alternância. Fazer valer esse direito é um dos grandes desafios que se coloca nos dias atuais, não somente para o campo na Amazônia, como também para o campo do Brasil.

\section{Origem e contexto histórico da pedagogia da alternância}

Nas últimas três décadas em diferentes estados brasileiros, vêm se desenvolvendo diversas experiências educativas que tomam como proposta pedagógica de ensino a Pedagogia da Alternância. Em nosso país o desenvolvimento da Pedagogia da Alternância ganha materialidade como estratégia de inúmeros movimentos sociais organizadas nos Centros Familiares de Formação em Alternância (CEFFAS).

Apesar da proposta pedagógica alcançar identificação principalmente com os grupos sociais ligados ao campo, não foi criada no Brasil. Surge na França em 1935, pensada pelo padre francês Abbé Granereau, pároco de uma pequena capela situada em uma localidade denominada de Sérignac - Péboudou, juntamente com um grupo de 
agricultores ligados à igreja católica, que iniciaram uma experiência piloto no povoado de Lanzun, utilizando o espaço da igreja para os encontros presenciais. Segundo Nosella (2007, p. 18):

[...] o jovem Granereau, esbarrava, de um lado, em um estado desinteressado dos problemas do campo e voltado única e exclusivamente para a fórmula escolar urbana; e, de outro lado, diante de uma igreja intencionalmente voltada para o homem do campo, mas sem nenhuma fórmula educacional capaz de responder realisticamente aos problemas da lavoura.

Diante daquela realidade, restava ao jovem padre uma alternativa: criar uma nova forma de organização da educação. Contudo, não foi casualidade essa tomada de posicionamento, pois o idealizador da Pedagogia da Alternância há muito tempo desenvolvia trabalhos junto aos sindicatos rurais, comunidades rurais e com as atividades da Igreja Católica. Nosella (2007) reitera que o jovem padre conhecia a realidade do meio rural, o que o possibilitou pensar em processos educacionais para os filhos dos agricultores.

A forma de aprendizado era uma novidade para os alunos do meio rural, pois alternava os tempos escolares: uma semana o jovem passaria nas dependências da igreja e duas ele ficaria na propriedade. Na semana na igreja desenvolveria diversas atividades educativas e nas semanas na comunidade reuniria elementos, observaria a realidade, sistematizaria as principais dificuldades das comunidades e da família e no retorno faria a socialização com os demais colegas na tentativa de encontrar soluções para as problemáticas que estavam sendo evidenciadas, sendo uma mistura de escola e casa, de tempos na escola e tempos com atividades na comunidade.

Segundo Gimonet (1999, p. 40) "fora de estruturas escolares e sem referência pedagógica, inventaram uma forma de educação que seus filhos não recusariam por que ela responderia as suas necessidades fundamentais”. Assim, começaram a desenvolver uma proposta de educação, tendo como princípio fundamental a participação de todos os sujeitos, entre eles, pais de alunos, as organizações locais e os membros da escola. O objetivo fundamental era trabalhar uma educação que fosse por um lado, atrativa para os jovens, e por outro, que os conteúdos fossem significativos e levassem em consideração a vida cotidiana.

Conforme Almada (2005, p. 43) inicialmente a experiência teve "apenas cinco jovens com idade entre 13 a 15 anos, que passavam três semanas em sua propriedade e uma semana de internato nas dependências da igreja". O nome foi escolhido em consequiência da forma como era organizado o aprendizado escolar, ou seja, funcionava como uma casa para os jovens rurais. A primeira escola foi batizada de Casa Familiar Rural de Lanzun, em homenagem ao pequeno povoado francês onde se localizava, sendo criada a primeira Maisons Familiales Rurales ou Casa Familiar Rural.

A primeira Casa Familiar Rural iniciou com poucos alunos, e logo após a formação da primeira turma surgiram mais alunos filhos de agricultores interessados em estudar em uma escola que tinha como proposta pedagógica a Pedagogia da Alternância. A proposta começa a fortalecer-se entre as duas guerras mundiais, num contexto de profunda crise da agricultura e outros setores. A proposta de uma escola que alternasse tempos e espaços de aprendizagem e fosse organizada a partir da realidade e das necessidades dos jovens agricultores, poderia ser uma alternativa viável para a complexa situação socioeconômica das famílias do meio rural francês. 
Segundo Nosella (2007, p. 81) "o objetivo da Pedagogia da Alternância não foi o de melhorar a escola tradicional, mas sim, criar outra escola". As palavras do autor expressam que a intencionalidade da proposta pedagógica não era fazer uma intervenção no sistema educacional francês, mas propor outros princípios, diretrizes, conceitos e perspectivas para a educação do meio rural.

Primeiramente, há que se reconhecer que quando os trabalhadores rurais franceses pensaram em uma forma diferenciada de educação, estavam também intrínsecas intencionalidades políticas. E o momento histórico era oportuno, pois a realidade do meio rural francês apontava para as lacunas que o Estado deixava na oferta educacional para os alunos do campo, e isso se concretizava em uma forma de subtrair a autonomia e a tutela do Estado em propor a educação para o meio rural. Os motivos para a emergência de outra forma de educação para o meio rural tinham suas razões no momento histórico em que a França vivenciava e as condições de oferta educacional para o campo. Segundo Silva $M$ (2003, p. 19) à época de seu surgimento, "apenas 3 a $4 \%$ dos jovens rurais franceses recebiam uma formação profissional dispensados pelos organismos públicos ou privados em decorrência da veiculação cada vez mais intensa da desvalorização do campo".

Para tanto, propuseram uma forma diferente para contrapor a educação que historicamente se tinha. Depois, não seria interessante apenas pensar em uma forma de educação, mas sim, uma educação que viesse ao encontro dos anseios dos alunos, filhos dos agricultores. Nesse sentido, suas intencionalidades estavam fundamentadas no sentido da proposição da questão educacional, pois reconheciam que a responsabilidade em prover financeiramente o ensino era do Estado, e este não estava cumprindo o seu papel. Então restava aos trabalhadores do meio rural propor uma forma de educação que contemplasse suas demandas.

No Brasil, as experiências que adotam a Pedagogia da Alternância chegaram primeiramente através de dois modelos: As Escolas Famílias Agrícolas e as Casas Familiares Rurais. As Escolas Famílias Agrícolas (EFA’s) foram implantadas no Espírito Santo no ano de 1969 e são organizadas e gerenciadas pela União Nacional das Escolas Família Agrícola do Brasil (UNEFAB). As Casas Familiares Rurais (CFR's) nasceram no Estado do Paraná no ano de 1987 e são gerenciadas pela Associação Regional das Casas Familiares Rurais (ARCAFAR). Tais experiências fazem parte dos Centros Familiar de Formação por Alternância (CEFFA) e se referem a todos os projetos educacionais que adotam a Pedagogia da Alternância independente da rede a qual faça parte, funcionando em torno de 217 escolas em aproximadamente vinte estados brasileiros.

Atualmente as Casas Familiares Rurais, são as mais expandidas em nosso país, encontra-se nos diversos continentes, estando presente de acordo com Gimonet (1999) em 28 países nos 05 continentes e com aproximadamente 1000 centros familiares. A implantação das CFR's no Brasil teve seu pontapé inicial com a vinda de um assessor técnico da União Nacional das Maisons Familiales Rurales, entidade que organiza na França as Casas Familiares Rurais, que tinha como objetivo divulgar e incentivar a implantação das experiências no Brasil. Esse suporte técnico e pedagógico contribuiu para a expansão da experiência para os outros estados brasileiros.

Colossi e Estevam (2003) assinalam que no Brasil as primeiras experiências datam no ano de 1981 no Município de Arapiraca, Estado de Alagoas e posteriormente em 1984 no Estado de Pernambuco. Em 1994, como uma forte expressão dessa expansão o governo do Paraná oficializou o Programa de Apoio à Implantação de Casas Familiares Rurais. Esse apoio tinha como objetivo alcançar as seguintes metas: Auxilio a difusão do programa, assessoria técnica e o acompanhamento às comunidades que desejassem fazer parte do programa, equipamentos, material didático e pedagógico, contratação de pessoal, 
elaboração da proposta curricular. Com esse apoio as CFR's se fortaleceram e expandiram para outras regiões.

Segundo a ARCAFAR Norte (2000b) em informações contidas no documento intitulado "Programa de Educação Rural para o Estado do Pará" a proposta de instalação da Casa Familiar Rural nasceu do anseio dos agricultores, lideranças e profissionais da educação, preocupados com a busca de uma alternativa de ensino para os jovens residentes no meio rural. As primeiras discussões iniciam-se no ano de 1994, em um encontro em Altamira promovido pelo Movimento pela Sobrevivência da Transamazônica (MPST) em parceria com o Laboratório Agroecológico da Transamazônica (LAET) que contou com a presença de um assessor das Casas Familiares da França.

No Estado do Pará existem cerca de 20 Casas Familiares Rurais, 15 em pleno funcionamento. Esse movimento começa a se fortalecer através da aproximação das experiências com a universidade e o governo. Uma evidência dessa colocação é a indicação pelos movimentos sociais do representante da ARCAFAR/PA, para compor o Conselho Estadual de Educação. No atual contexto de fortalecimento da Educação do Campo está sendo proposto que a Pedagogia da Alternância seja levada em consideração como proposta de organização do ensino para as escolas do campo.

\subsection{Educação do campo e pedagogia da alternância: marco legal}

A necessidade de políticas públicas específicas para o campo vem nos últimos anos norteando o debate que se estabelece acerca da educação para o meio rural. A seguir destacaremos alguns pontos fundamentais que têm sido evidenciados pelo movimento em defesa da educação do campo: a inclusão das demandas do campo na agenda pública do país e a construção de políticas públicas específicas para os povos do campo.

Um aspecto fundamental que não pode ficar ausente das discussões acerca das políticas educacionais para o campo, é o reconhecimento por parte daqueles que elaboram as políticas públicas de que o campo está vivo e em constante movimento. Nesse sentido, Caldart (2000, p. 41) afirma que o campo no Brasil é um espaço de tensões, lutas sociais, organizações e movimentos de trabalhadores e trabalhadoras da terra que estão mudando o jeito da sociedade olhar para o campo e seus sujeitos. Esse movimento percebe que é a escola que deve a ele se ajustar, em sua forma e conteúdo, aos sujeitos que dela necessitam; é a escola que deve ir ao encontro dos educandos, e não o contrário.

De 1998 até 2007 houve avanços fundamentais na afirmação da Educação do Campo, principalmente no que tange às políticas públicas. Anterior a esse período, temos a Lei de Diretrizes e Bases da Educação Nacional (9394/96) que reconhece em seu artigo $1^{\circ}$ que "os processos formativos se desenvolvem na vida familiar, na convivência humana, no trabalho, nas instituições de ensino e pesquisa, nos movimentos sociais, organizações da sociedade civil e nas manifestações culturais". Esse parágrafo se constitui um marco legal importante para a Educação do Campo, uma vez que reconhece que outros espaços socioeducativos podem contribuir com a formação dos jovens.

Essa abertura deixa espaço para que as diversas experiências de educação popular possam ser consideradas e incorporadas na instituição das políticas públicas. Na mesma Lei, o artigo 28, pontua questões relevantes para o fortalecimento da Educação do campo, que não estavam anteriormente contempladas, e que deveriam seguir na perspectiva da transformação da realidade educacional do campo. Dispõe o texto: 
$\mathrm{Na}$ oferta de educação básica para a população rural, os sistemas de ensino promoverão as adaptações necessárias à sua adequação, às peculiaridades da vida rural e de cada região, especialmente no que tange aos conteúdos curriculares e metodologias apropriadas às reais necessidades e interesses dos alunos da zona rural; organização escolar própria, incluindo adequação do calendário escolar às fases do ciclo agrícola e às condições climáticas; e adequação à natureza do trabalho na zona rural.

Eis o grande nó da questão, promover "tais adaptações", pois, como vimos anteriormente no retrato das escolas do campo, a realidade que se apresenta não está em sintonia com as questões legais. Contudo, nenhuma lei por si só transforma a realidade, são necessárias políticas públicas que possam dar-lhe materialidade. Diante da precariedade da oferta educacional presente no meio rural, onde a maioria das escolas funciona em barracões comunitários que não oferecem condições de aprendizagem, promover as adequações não somente são necessárias como de vital importância para os processos educacionais que se desenvolvem no campo. Se por um lado, estas questões não estão sendo materializadas nos municípios brasileiros, por outro, oferece um leque de possibilidades de discussões, que já se fazem sentir nos diversos espaços de diálogo que nos últimos anos foram sendo criados, como resultado dos embates e das pressões dos movimentos sociais do campo.

Em consequiência das pressões dos movimentos sociais, tem-se em 2002 a aprovação das Diretrizes Operacionais para a Educação Básica nas Escolas do Campo, pelo Conselho Nacional de Educação/CEB, apresentando-se como um avanço das discussões, pontuando em seu parágrafo único que [...] a identidade da escola do campo é definida pela sua vinculação às questões inerentes a sua realidade. As diretrizes explicitam a identidade da escola não circunscrita a um espaço geográfico, mas definida a partir da realidade, da cultura e modos de vida dos sujeitos sociais, o que tem sido um grande avanço em termos do reconhecimento das especificidades da educação e da escola do campo.

Nesse processo a atuação dos movimentos sociais tem sido extremamente positiva, no sentido de que tais demandas fossem incluídas e reconhecidas pela agenda educacional de nosso país. Ao que tudo indica, esse parágrafo das diretrizes tem sido um marco para o fortalecimento da Educação do Campo, porque pontua que a educação não se restringe somente aos espaços escolares, mas envolve outros espaços socioeducativos, o que dá uma significativa margem para que os movimentos sociais que desenvolvem experiências com base na Pedagogia da Alternância sejam fortalecidos.

Em 2006 a aprovação do Parecer $n^{\circ}$ 01/2006 que reconhece os dias letivos para a aplicação da alternância foi um marco significativo para a história da Pedagogia da Alternância. Esse parecer é um avanço importante, uma vez que um dos grandes problemas enfrentados pelas experiências que adotam a Pedagogia da Alternância é o processo de certificação. O reconhecimento dos dias letivos para a aplicação da Alternância possibilita o reconhecimento legal dos CEFFA's e conseqüentemente a certificação dos jovens.

A aprovação deste parecer significa o reconhecimento do que pontua a Lei de Diretrizes e Bases da Educação (9394/96) que reconhece que a educação não acontece somente nos espaços de sala de aula, mas desenvolve-se também em outros espaços socioeducativos. É o reconhecimento do trabalho que os inúmeros movimentos sociais vêm desenvolvendo no campo, e que fogem ao padrão da escolarização adotado nos sistemas de ensino no Brasil. 
Por outro lado, acena para a abertura de canais de diálogo entre governo e movimentos sociais, no sentido de se estabelecer parcerias com as experiências educativas que vêm acontecendo no Brasil através dos movimentos sociais, ONGs e outras instituições no sentido de legitimá-las enquanto políticas públicas. Também o parecer pode ser uma evidência de que as experiências educacionais que os movimentos sociais do campo vêm desenvolvendo pode ser uma alternativa viável para atender as expectativas do jovem rural.

Anterior a esse movimento, em 2003 foi constituído o Grupo Permanente de Trabalho e Educação do Campo e em 2004 foi criada a Secretaria de Educação Continuada, Alfabetização e Diversidade (SECAD) com o objetivo de servir de espaços de discussão coletiva, articulando as ações dos Ministérios (Educação e Desenvolvimento Agrário) em relação à implementação das Diretrizes Operacionais para as Escolas do Campo. Ao mesmo tempo, se fortalecem diversos espaços de discussões entre eles, Conferências, Fórum, Palestras, criação de Grupos de Trabalhos, Grupos de Pesquisas, dissertações, teses, etc., mostrando que a educação para os filhos dos trabalhadores deve ter um lugar na agenda política do país. Mas apesar de todos esses avanços, percebe-se que o caminho é longo e que o processo é lento.

Nos diversos estudos analisados, constatamos que do ponto de vista das questões legais houve grandes avanços. A problemática que se apresenta é exatamente legitimar e efetivar as questões pontuadas em lei. Entretanto, o que se observa ao analisar a realidade brasileira é que existe um grande distanciamento das questões legais e sua operacionalização. Arroyo (1982 a, p. 15) pontua que "entre a intenção de uma política expressa no discurso e na lei e sua implementação há grande distância". Ainda hoje, na maioria dos municípios brasileiros, a educação desenvolvida no meio rural traz como modelo pedagógico uma única forma de entender e de trabalhar os processos formativos, caminhando em sentido oposto ao que vêm sendo defendido pelos movimentos sociais e indicado na legislação vigente.

Eis o grande desafio a ser enfrentado pelos educadores, gestores, Poder Público, movimentos sociais e outros, fazer valer o que tem sido de direito, mas não de fato, construir uma Educação do Campo que dê conta de contemplar a heterogeneidade e a diversidade do campo brasileiro e amazônico.

\section{Os desafios da educação do campo na Amazônia}

Discutir a educação, em especial a Educação do Campo na Amazônia é um desafio. Requer fundamentalmente que se reflita sobre a heterogeneidade e diversidade cultural existente na Amazônia e como estas são pontuadas no desenho das políticas públicas educacionais. Para a compreensão desta realidade utilizamo-nos de um conjunto de autores locais que realizam estudos e pesquisas acerca da realidade educacional amazônica contribuindo com importantes questões para o debate.

De acordo com Cristo et al (2005) a Amazônia possui uma riqueza cultural muito vasta que se expressa de forma significativa nas lendas, danças, histórias que compõem o imaginário sociocultural das populações rurais e ribeirinhas. De acordo com os autores, toda essa riqueza é ignorada pela cultura urbana que gradativamente vai desconstruindo e desvalorizando o imaginário das populações rurais e ribeirinhas. Esse processo de desvalorização do saber das comunidades tradicionais surge em conseqüência de um processo histórico de submissão dos valores urbanos sobre os valores do meio rural.

Hage (2005a) destaca que a Amazônia apresenta como uma de suas características fundamentais a "heterogeneidade". Entretanto, historicamente, essa heterogeneidade 
quando analisada no âmbito de nossas políticas públicas tem sido desconsiderada. Essas afirmações são reforçadas pelo Grupo de Estudo e Pesquisa em Educação do Campo na Amazônia, sintetizada na obra Educação do Campo na Amazônia: Retratos e realidade das escolas multisseriadas no Pará (GEPERUAZ, 2005). Nela percebemos que ainda na maioria dos municípios paraenses a educação que é ofertada para o meio rural traz como modelo pedagógico uma única forma de entender e de trabalhar os processos formativos, caminhando em sentido oposto ao que vêm sendo defendido pelo movimento por uma Educação do Campo.

Segundo Hage, a realidade vivenciada pelos sujeitos nas escolas existentes no campo evidencia grandes desafios a serem enfrentados para que sejam cumpridos os marcos operacionais anunciados nas legislações educacionais, uma vez que a realidade que se apresenta são denunciadoras e preocupante. Na Amzônia, de acordo com Hage (2005b, 44) "[...] 29,9\% da população adulta é analfabeta; 3,3 anos é a média de anos de escolarização dessa população; e $71,7 \%$ das escolas que oferecem o ensino fundamental nas séries iniciais são exclusivamente multisseriadas, atendendo 46,6\% dos estudantes em condições precárias".

Os dados acima nos revelam que somente a institucionalização de leis não é suficiente para mudar o retrato educacional do campo, pois muito ainda precisa ser feito para que os aspectos legais sejam legitimados, muitos desafios precisam ser vencidos. Esses dados evidenciam uma realidade já conhecida, mas que precisa a todo o momento ser relembrada, destacada, pontuada e pautada no âmbito das políticas públicas. Em nosso entendimento, as políticas sociais não podem ser compensatórias nem passageiras, devem ser políticas de Estado, para que possam assim, contribuir para redesenhar o retrato de nossas escolas rurais.

Ao analisar a realidade educacional amazônica constata-se que as insuficiências da ação do Estado no meio rural são latentes, não somente relacionados ao aspecto educacional, assim como a outros direitos constitucionais. Se por um lado, atesta a incapacidade do Estado de atender a grande diversidade e heterogeneidade dos povos da floresta, dos rios e das águas, por outro, denuncia que um dos marcos fundamental da Constituição Federal, o direito à educação, não vem sendo negado a um considerável contingente populacional.

Na Região Amazônica, considerando-se os dados apresentados, pode-se concluir que as respostas do Estado às demandas da sociedade têm-se demonstrado insatisfatórias. Isso é atestado se analisarmos mais detidamente as condições de oferta da educação para o meio rural. Souza e Oliveira (2003) destacam que as instituições responsáveis pela educação no meio rural pouco levaram em consideração ou deixaram cair no esquecimento as demandas e os direitos da maioria da população rural, não ofertando infra-estrutura material e pedagógica com qualidade e quantidade satisfatórias.

Para além de suas riquezas naturais e culturais, na Região Amazônica a realidade socioeconômica e educacional nos permite assegurar, com certo grau de convicção, que os direitos sociais dos sujeitos do campo vêm sendo negados. Essa preocupante ponderação ancora-se na perspectiva de que a oferta dos direitos básicos ao campo segue na perspectiva de oferecer, como destaca Souza (2005, p. 07) "uma educação pobre aos pobres do campo".

As conseqüências desse histórico abandono pelo qual passa a região e conseqüentemente, os povos do campo, são denunciadores de uma realidade preocupante. No caso paraense, predomina nas escolas do campo as classes multisseriadas. São escolas funcionando em condições precárias que seguem a perspectiva de manter um mesmo professor com duas, três ou quatro séries num mesmo espaço e tempo. De acordo com 
Hage (2005b) no meio rural do Estado do Pará as escolas multisseriadas são a modalidade predominante e somam em torno de $97,45 \%$ as matrículas no primeiro segmento do ensino fundamental. Nessas escolas, a taxa de distorção idade série é de $81,2 \%$, chegando a $90,51 \%$ das crianças matriculadas na $4^{\mathrm{a}}$ série; e a taxa de reprovação equivalente a $23,36 \%$, atingindo um índice de $36,27 \%$ na $1^{\mathrm{a}}$ série.

Esse é somente um aspecto da realidade rural amazônica, outros aspectos também se apresentam com bastante intensidade e dificultam cada vez mais o cotidiano dos sujeitos do campo. Entre eles podemos citar a precária condição estrutural em que as escolas funcionam, algumas vezes em barracões comunitários, onde as condições físicas não favorecem a aprendizagem; a escassa oferta de material didático e pedagógico; a delicada oferta do transporte escolar e falta de formação dos docentes, o currículo deslocado da realidade local são alguns dos aspectos que torna a educação do campo na Amazônia, carente de políticas públicas educacionais que dêem conta de contemplar sua realidade complexa e heterogênea.

Essas condições de oferta podem induzir-nos a imaginar a qualidade da educação desenvolvida nesses espaços. Permite também perceber a carência não somente de políticas públicas capazes de minimizar os muitos obstáculos dos sujeitos do campo, como também, capazes de incentivar e impulsionar uma nova dinâmica para as escolas do campo, delineando novos olhares para as perspectivas de que as melhores escolas e a educação de qualidade estão localizadas na cidade.

Na Região Amazônica e especificamente no Estado do Pará, se vive um paradoxo, onde coexistem a diversidade e a precariedade ao mesmo tempo. Diversidade atestada pelo número significativo de povos e etnias existentes na região com diferentes costumes, culturas, modos de vida e de trabalho, por outro lado, vivendo em precárias condições de vida, de trabalho, de saúde e de educação.

Silva e Leão (2005), ao refletir sobre a realidade educacional em comunidades remanescentes de quilombos em nosso Estado nos municípios de Cametá, Moju e Mocajuba pontuam que nas escolas rurais localizadas nas comunidades remanescentes de quilombo, as dinâmicas escolares e as perspectivas educacionais não se diferem da realidade educacional do restante da região amazônica e refletem o descaso do poder público no âmbito federal, estadual e municipal à educação e às escolas situadas nessas comunidades.

De acordo com os autores, a realidade educacional nas comunidades remanescentes de quilombo é precária e precisa urgentemente da implementação de políticas públicas que sejam capazes de melhorar a situação existencial das escolas nas comunidades remanescentes de quilombo. Em que pese às recomendações legais relacionadas às adaptações das escolas do campo, as peculiaridades locais, destacadas no artigo 28 da Lei de Diretrizes e Bases da Educação Nacional, o que se observa é que ainda prevalece a lógica urbanocêntrica e um currículo que segue na perspectiva de tratar a todos de forma homogeneizadora. Essa lógica, de acordo com Silva e Leão (Op.Cit., p. 270) "ainda domina e orienta as práticas didáticas e pedagógicas dos conteúdos disciplinares das escolas das comunidades tradicionais do campo, o que tem refletido nas reprovações, evasões e repetências de muitos alunos".

A realidade destacada nesses estudos são evidências de que o modelo adotado na região e no Estado do Pará não contempla as reais necessidades sociais, econômicas, culturais e educacionais dos sujeitos do campo. Identifica-se que a realidade das escolas rurais fere os princípios constitucionais e nega aos sujeitos do campo o direito de ter educação no lugar onde vive, com respeito a sua cultura e seu modo de vida. As 
consequiências desse processo tem sido desastrosa para os sujeitos do campo, uma vez que o mesmo nega a identidade dos sujeitos.

\section{Considerações}

Refletir sobre a educação para os sujeitos que vivem no campo brasileiro e amazônico no contexto atual é um desafio. Essa assertiva pode ser reforçada ao analisarmos as condições socioeconômicas e educacionais dos sujeitos que vivem no campo, onde segundo o Instituto Nacional de Estudos e Pesquisas Educacionais Anísio Teixeira (2007), cerca de 30,8 milhões de brasileiros que vivem no campo encontra-se em franca desvantagem, tanto em termos de recursos financeiros (capital físico) quanto em termos de escolaridade (capital sociocultural) se comparado com os dados da população da área urbana.

O movimento em defesa da Educação do Campo tem se fortalecido com a adesão de inúmeros sujeitos, a despeito dos governos, Federal, Estadual e Municipal, de organizações não-governamentais, associações, sindicatos, confederações de trabalhadores e outros. Apesar dessa adesão no que tange as políticas públicas, o que tem sido legitimado não tem sido suficientemente satisfatório para atender as necessidades dos sujeitos. Nesse sentido, na modalidade da Educação do Campo, apesar de alguns avanços na legislação, suas insuficiências ainda são latentes se observarmos a realidade da educação e das escolas do campo.

Apesar de se reconhecer que no meio rural vivem parcela importante da população brasileira, historicamente as políticas públicas sociais direcionadas a esse setor seguiram a perspectiva de atender aos interesses das classes que se encontravam no poder. Ao analisar as políticas publicas educacionais que têm sido direcionadas ao campo chega-se à conclusão de que escola, ao longo dos anos, tem servido à classe dominante, sendo inacessível para grande parte da população rural, principalmente pela concepção vigente de que para desenvolver o trabalho no campo não seria imprescindível a apreensão dos códigos da leitura e da escrita.

Nossa história tem demonstrado que as políticas públicas que seguem essa perspectiva não tem sido exitosas, uma vez que nega a própria identidade dos sujeitos do campo em diferentes aspectos. Pode se inferir, entretanto, que as condições educacionais que se desenvolvem nesse cotidiano condenam o aluno a uma educação precária. Esse contexto tem suas origens na forma como as políticas públicas são pensadas e direcionadas ao campo, não considerando que nele existem inúmeros sujeitos com necessidades específicas. Nessa lógica urbanocêntrica, para os sujeitos do campo não são necessárias políticas públicas específicas, pois se encontram fora do lugar no projeto de desenvolvimento do país.

Atualmente, essa realidade vem sendo modificada, seja pelas inúmeras tensões no campo, na luta pela reforma agrária ou seja pela crescente mobilização social de trabalhadores do campo e de diferentes entidades e órgãos públicos, que dão novos contornos às políticas públicas educacionais. Nessa trajetória de luta pela garantia de direitos sociais, temos a constituição de diversos sujeitos coletivos, isso por que, como assinala Bourdieu (2004, p. 26) "o espaço social, bem como os grupos que nele se distribuem, são produtos de lutas históricas". Tais sujeitos encontram-se nos diversos movimentos que vão ao enfrentamento no campo das políticas sociais, pois reconhecem que somente o direito à terra não é suficiente, são necessárias outras políticas, entre elas 
reconhecem a real importância da educação nos processos de lutas que se dão no campo brasileiro.

Para os povos do campo que não fazem a separação entre educação/trabalho, educação/vida, essas transformações têm sido excludentes, pois esse modelo não reconhece o campo como lugar de vida, espaço de tensões e conflitos, e, portanto, não consegue incluir a grande diversidade de sujeitos que vivem no campo e que possuem necessidades humanas e sociais específicas e variadas. Nesse contexto, esses povos têm se mobilizado para a superação da histórica dicotomia urbano/rural, campo/cidade, no sentido de perceber esses espaços como complementares e interdependentes, uma vez que há traços marcantes da cidade no campo e traços do campo na cidade.

Em que pese todos esses avanços, o meio rural ainda necessita de atenção e reflexões. Nossa história tem evidenciado que o direito à educação que contemple as realidades e necessidades dos cidadãos vem sendo negado à parcela significativa da população. Analisar a importância as diversas experiências popular de educação requer reconhecer todo um esforço que vem sendo realizado por inúmeros sujeitos na perspectiva da criação de uma proposta educacional aos jovens do campo. Significa reconhecer que a educação não acontece somente nos espaços de sala de aula, mas existem outros espaços socioeducativos que podem contribuir significativamente com a formação dos jovens do campo do campo brasileiro e amazonico.

\section{Referências}

ALMADA, Francisco de Assis Carvalho de. A experiência educ ativa de uma Casa Familiar Rural e suas contribuições para o desenvolvimento local. Belém: Dissertação de Mestrado em Planejamento do Desenvolvimento Socioambiental, UFPA/NAEA, 2005.

ARROYO, Miguel Gonzalez. Educação para as novas relações de trabalho no campo. In: Seminário Educação no meio rural (Anais). Brasília: INEP, 1982a.

A educação básica e o movimento social do campo. In: ARROYO, Miguel Gonzalez; FERNANDES, Bernardo Mançano (Orgs). A educação básica e o movimento social do campo. Coleção por uma educação básica do campo. $\mathrm{n}^{0} 2$, Brasília, DF. Articulação Nacional Por Uma Educação do Campo, 1999.

ASSOCIAÇÃO REGIONAL DAS CASAS FAMILIARES RURAIS DO NORTE E NORDESTE (ARCAFAR). Programa de Educação Rural para o Estado do Pará. Altamira: [S. 1.], $2000 b$.

BRASIL/MEC. Dias Letivos para a aplicação da Alternância nos Centros Familiares de Formação por Alternância. Parecer nº 01/2006, 2006, Brasília.

Brasília.

. Lei de Diretrizes e Bases da Educação Nacional. Lei no 9394/96. 1996,

Diretrizes Operacionais para a Educação Básica nas escolas do campo.

Resolução no 01/2002, 2002, Brasília. 
GRUPO PERMANENTE DE TRABALHO DE EDUCAÇÃO DO CAMPO.

Referências para uma Política Nacional de Educação do Campo (Caderno de Subsídios). Brasília-DF, 2005.

CALDART, Roseli Salete. A Escola do Campo em Movimento. In: BENJAMIN, Cesar; CALDART, Roseli Salete. (Orgs). Por uma Educação Básica do Campo. Coleção por uma educação básica no campo. no 03, Brasília: DF. Articulação Nacional Por Uma Educação do Campo, 2000.

Roseli Salete. Por uma Educação do campo: Traços de uma identidade. In: Kolling, Edgar Jorge et all (org). Educação do Campo: Identidade e Políticas Públicas. Coleção Por uma educação do campo. n ${ }^{\circ}$ 04, Brasília: DF. Articulação Nacional Por Uma Educação do Campo, 2002.

COLOSSI, Nelson; ESTEVAM, Dimas de Oliveira. Casas Familiares Rurais: Uma alternativa para a formação de jovens agricultores. Revista de Administração (periódico). Gráfica Editora, 2003.

CRISTO, Ana Cláudia Peixoto de; NETO, Francisco Costa Leite; COUTO, Jeovani de Jesus. Educação Rural Ribeirinha Marajoara: Desafios no contexto das escolas multisseriadas. In: HAGE, Salomão Mufarrej (Org). Educação do Campo na Amazônia: Retratos e realidades das Escolas Multisseriadas no Pará. Belém: Gráfica e Editora Gutemberg Ltda, 2005.

GIMONET, Jean Claude. Nascimento e Desenvolvimento de um movimento educativo: As Casas Familiares Rurais de Educação e de Reorientação. I Seminário Internacional da Pedagogia da Alternância. Salvador, 1999.

HAGE, Salomão Mufarrej. Classes Multisseriadas: desafios da educação rural no Estado do Pará/Região Amazônica. In: HAGE, Salomão Mufarrej (Org). Educação do Campo na Amazônia: Retratos e realidades das Escolas Multisseriadas no Pará. Belém: Gráfica e Editora Gutemberg Ltda, 2005b.

. Educação na Amazônia: Identificando singularidades e suas implicações para a construção de propostas e políticas educativas e curriculares. In: HAGE, Salomão Mufarrej (Org). Educação do Campo na Amazônia: Retratos e realidades das Escolas Multisseriadas no Pará. Belém: Gráfica e Editora Gutemberg Ltda, 2005a.

II Seminário Estadual de Educação do Campo. Caderno de Textos. Contribuições para o debate. Belém: Fórum Paraense de Educação do Campo, 2005.

III Seminário Estadual de Educação do Campo. Caderno de Textos. Contribuições para o debate. Belém: Fórum Paraense de Educação do Campo, 2007.

INSTITUTO NACIONAL DE ESTUDOS E PESQUISA ANÍZIO TEIXEIRA. Panorama de Educação no Campo. Brasília: INEP, Janeiro: Paz e Terra, 2007. 
Manifesto do II Seminário Estadual de Educação do Campo, da Floresta e das Águas da Amazônia Paraense. In: III Seminário Estadual de Educação do Campo. Caderno de Textos: Contribuições para o debate. Belém, 2007.

NOSELLA, Paolo. As origens da Pedagogia da Alternância. Brasília: UNEFAB, 2007.

SILVA, Gillys Vieira da; LEÃO, Jacinto Pedro Pinto. Territórios quilombolas do Pará: Os saberes das ciências das comunidades negras. In: HAGE, Salomão Mufarrej (Org). Educação do Campo na Amazônia: Retratos e realidades das Escolas Multisseriadas no Pará. Belém: Gráfica e Editora Gutemberg Ltda, 2005.

SILVA, Lourdes Helena et al. A Educação no Meio Rural do Brasil: Revisão da Literatura. In: BOF, Maria Alvana (Org); SAMPAIO, Carlos Eduardo Moreno et all. A Educação no Brasil Rural. Brasília: Instituto Nacional de Estudos e Pesquisas Educacionais Anísio Teixeira, 2006.

SILVA, Marizete Fonseca da. Pensar o trabalho é pensar a vida: As dimensões da formação na Pedagogia da Alternância da Escola Família Agrícola de Marabá-PA. Belém: Dissertação de Mestrado em Agricultura Familiar e Desenvolvimento Sustentável. UFPA, 2003.

SOUZA, Orlando Nobre B. de. Contextualizando a Educação do Campo na Amazônia/Pará. In: II Seminário Estadual de Educação do Campo. Por uma Educação do Campo na Amazônia/ Pará. Caderno de textos. Belém, 2005.

SOUZA, Orlando Nobre B. de; OLIVEIRA, Ney Cristina M. de. Cultura, Educação e Participação Social: desafios educativos no contexto amazônico. In: ARAUJO, Ronaldo Marcos de Lima (Org). Pesquisa em Educação no Pará. Belém: EDUFPA, 2003.

I CONFERÊNCIA POR UMA EDUCAÇÃO BÁSICA DO CAMPO. Texto Base. In: Kolling, Edgar Jorge et all (org). Por uma Educação do Campo: Identidade e Políticas Públicas. Coleção Por Uma Educação do Campo, nº 02, Brasília, DF: Articulação Nacional Por Uma Educação do Campo, 1999.

Notas

\footnotetext{
${ }^{1}$ Pedagoga e Mestre em Educação pela Universidade Federal do Pará (UFPA) Doutoranda em Educação pela Universidade Estadual de Ponta Grossa (UEPG). Docente da Universidade Federal do Pará/UFPA e membro do Grupo de Estudo em Educação do Campo da Região Tocantina (GEPECART). E-mail: suelicorrea@ufpa.br
}

Recebido em julho-2013

Aprovado em setembro-2013 